\title{
Conferencia a los estudiantes de primer ingreso: \\ El quehacer del economista
}

Jaime Ros*

Buenas tardes a todos. El director de la Facultad de Economía me ha otorgado la distinción de dirigirme a ustedes para hablar del quehacer del economista y darles la bienvenida a nuestra Facultad, distinción que le agradezco muy sinceramente.

Antes de volver hace tres años a México y a la UNAM, donde estudié hace muchos años (prefiero no contar cuantos), viví 20 años en Estados Unidos donde enseñé economía en la Universidad de Notre Dame. Es muy común en Estados Unidos, en la academia incluida, empezar una conferencia contando un chiste. Debo confesar que al principio me "sacaba mucho de onda" esta manera de introducir un tema, que a veces era muy serio e incluso grave, pero eventualmente me acostumbré y creo haber entendido el propósito de este recurso: romper el hielo, es decir, relajar al público y relajarse uno mismo quitándole el carácter ceremonioso que de otra manera tendría la reunión entre el conferencista y su público. De manera que por primera vez en mi vida, voy a empezar una charla con un chiste, en este caso sobre la disciplina que se han embarcado a estudiar, o, más bien, con algo que parece un chiste pero en realidad es un reflejo fiel (y no distorsionado de la realidad).

La afirmación dice así: "El de la economía es el único campo en el que dos personas pueden obtener el premio Nobel por decir uno exactamente lo contrario del otro". Para convencerlos de que no es en realidad un chiste déjenme darles algunos ejemplos. Milton Friedman recibió el premio en 1976 por sus aportaciones a la teoría monetaria y James Tobin en 1981 por su contribución a una teoría monetaria completamente distinta; Bertil Ohlin lo obtuvo en 1977 por su contribución a la teoría neoclásica del comercio internacional y Paul Krugman en 2008 por su aporte a la nueva teoría del comercio internacional, crítica de la teoría neoclásica; Robert Lucas (1995) y Daniel Kahneman (2002) lo obtuvieron por visiones completamente encontradas de la racionalidad económica y la incertidumbre. De hecho se puede agregar a la afirmación anterior que no solo se puede obtener un Premio Nobel por decir lo contrario que 
Economía Informa núm. 383 noviembre - diciembre • 2013 | " " "

otro Premio Nobel. Se puede compartir el mismo Premio Nobel por decir lo opuesto que el economista con el que se comparte el premio. El caso más connotado es el de Friederich Hayek, el archienemigo de Keynes, y Gunnar Myrdal, precursor de la teoría macroeconómica keynesiana, que lo obtuvieron en 1974 por "su trabajo pionero en la teoría del dinero y las fluctuaciones económicas y por sus penetrantes análisis de la interdependencia de los fenómenos económicos, sociales e institucionales" Otro caso es el de Arthur Lewis y Teodoro Schultz que lo compartieron en 1979 por contribuciones completamente opuestas a la teoría del desarrollo económico.

¿Quiere decir todo esto que han escogido entonces una carrera llena de arenas movedizas? Sí, pero antes de abordar esta pregunta, quiero hablar de la importancia social de la economía e ilustrarla con dos ejemplos: la crisis económica mundial y el estancamiento económico de México.

\section{La crisis económica mundial y los cambios de paradigma}

Si echamos un vistazo a las economías desarrolladas, las economías de los países ricos, vemos a una Europa en crisis profunda que ha llevado a una crisis social y política en algunos casos, y a unos Estados Unidos entrampados todavía en lo que se ha llamado la Gran Recesión. El origen de esta situación se remonta a la crisis financiera y económica mundial de los últimos años, una crisis de gran envergadura que tendrá probablemente importantes repercusiones en años por venir en nuestra disciplina, en particular en la teoría macroeconómica y su enseñanza. Se ha vuelto un lugar común decir que nuestra disciplina fue incapaz de predecir la crisis de mayores proporciones desde la de los años treinta del siglo pasado a lo que se puede agregar que la única respuesta de la economía ortodoxa a esta crítica es que las crisis son imposibles de predecir porque ningún agente económico tiene mejor información individualmente que la que tienen los mercados que colectivamente reúnen la información ampliamente dispersa entre los individuos. Ello y el espectáculo que ofrecen las controversias entre economistas de distintos bandos, que repiten en gran medida los debates de política macroeconómica de los años 1930, cuando la macroeconomía nació como disciplina con la publicación de la Teoría General de la ocupación, el interés y el dinero (1936) de Keynes, han llevado al público en general a abrigar graves dudas sobre la seriedad de la disciplina. Como lo ha dicho la revista británica The Economist, de todas las burbujas económicas que han estallado, pocas lo han hecho tan espectacularmente como la reputación de la economía misma. Hace apenas unos años la "ciencia lúgubre" como la 
llamara el filósofo Thomas Carlyle era aclamada como una forma de explicar cada vez más fenómenos del comportamiento humano y los economistas eran vistos como mucho más confiables que otros científicos sociales, no se diga que los políticos. John McCain, el ex-candidato presidencial en Estados Unidos bromeaba que Alan Greenspan, entonces presidente de la Reserva Federal, el banco central de Estados Unidos y el banco más poderoso en la economía mundial, era tan indispensable que si muriera, el presidente tendría, un poco como al Cid campeador, que mantenerlo en su sillón y ponerle unos anteojos oscuros para que nadie se enterara de su deceso.

No cabe duda, en mi opinión, que los modelos macroeconómicos en voga durante el desenlace que estalló en la crisis de 2008 son una guía pobre para entender los orígenes de la crisis financiera y no proveen una buena guía para saber cual es la mejor manera de lograrla recuperación de la economía. Parece claro a estas alturas que la política monetaria es insuficiente para sacar a las economías de los países ricos del bache en que se encuentran y que muchos economistas entrenados en los métodos y visiones que han predominado en los últimos treinta años están mal preparados para decirnos como hacerlo. Un ejemplo de lo anterior es que ante la impotencia de la política monetaria, los gobiernos deben recurrir a la política fiscal si hay alguna esperanza de salir de la situación actual. Sin embargo, de los 7,000 artículos publicados por el National Bureau of Economic Research, por donde pasan la gran mayoría de los artículos que se publican en revistas académicas en Estados Unidos, entre 1985 y 2000 solo cinco mencionaron la política fiscal en su título o resumen del trabajo.

Esta situación ha llevado al economista Paul Krugman ha hablar de la situación que ha prevalecido en los últimos treinta años como "la edad obscura de la macroeconomía” (Krugman, 2011). En estos años, los últimos treinta, piensa Krugman, sucedieron dos cosas. En primer lugar, se destruyó conocimiento previamente acumulado con consecuencias sociales nefastas. En efecto, se repiten hoy, con una fe que no existía hace treinta o cuarenta años, las mismas falacias que se decían en los años treinta antes y después de la publicación de la Teoría General. En segundo lugar, en estos años, ha predominado una visión de la macroeconomía en la que se supone que los agentes económicos, con gran información sobre el funcionamiento de la economía y basados en las correspondientes expectativas racionales, formulan sus planes óptimos de producción, inversión, consumo, trabajo y ocio, y los mercados, en equilibrio continuo, se encargan de volver consistentes entre sí esos planes óptimos. Otra manera de referirse a esta visión es, en la expresión de Buiter 
Economía Informa núm. 383 noviembre - diciembre • 2013 | " " "

(1980), como la macroeconomía del Dr. Pangloss (El Dr. Pangloss era el tutor de Cándido en la obra de Voltaire que decía que todo está lo mejor posible en el mejor de los mundos posibles).

Todo esto no parece muy alentador: la disciplina no parece estar cumpliendo su función social al tiempo que ésta es de la mayor importancia. Pero si vemos más a fondo hay buenas razones para el optimismo. En primer lugar, las críticas más serias y profundas al estado de la disciplina provienen desde dentro de ésta, no de fuera. Y las hacen economistas prominentes, como Paul Krugman o Joseph Stiglitz entre otros, que se formaron en la corriente dominante de la economía, la conocen en profundidad y por ello sus críticas son válidas y valiosas. El consenso se ha roto por la necedad de los hechos pero las nuevas direcciones que tome el campo van a estar determinadas y requerir un conocimiento profundo de la disciplina misma y su estado actual. Un proceso de destrucción creativa, como llamara el gran economista Schumpeter a los efectos del progreso tecnológico, está en marcha y surge de las entrañas mismas de la disciplina. Esta es la única manera en que como profesionistas de la economía podemos contribuir a un cambio favorable a la sociedad.

\section{El estancamiento económico de México y los desafíos para los economistas mexicanos}

El segundo ejemplo que quiero usar para ilustrar la importancia social de la economía es el estancamiento que ha vivido la economía mexicana en los últimos treinta años. El ritmo de crecimiento de la economía mexicana desde principios de los años ochenta del siglo pasado ha estado muy por debajo de la norma histórica de las cuatro décadas anteriores y por ello los ingresos per cápita han divergido en lugar de converger hacia los niveles alcanzados por las economías industriales avanzadas. En el mundo en desarrollo, México es uno de los países de menor crecimiento en los últimos treinta años.

Muchos de los grandes problemas nacionales en la actualidad -desde la pobreza y la alta informalidad en el mercado de trabajo hasta el rezago en materia de educación y salud, la bomba de tiempo que representan las pensiones y la violencia en aumento asociada al crimen organizado- son en buena parte resultado de esta falta de crecimiento. Si el producto por trabajador en México hubiera continuado creciendo a la tasa del período 1950-1981, la transición a los niveles de ingreso alto se habría alcanzado durante las tres décadas pasadas. Con el incremento en la tasa de participación de la fuerza de 
W

trabajo desde 1981 (1.2\% por año) y el crecimiento del producto por trabajador de 1950 a 1981 (3.2\% por año), el ingreso per cápita habría alcanzado en 2007 el nivel promedio actual de los países de ingreso alto de la OCDE (y habría estado muy por encima de los niveles de 1980 de esos países). Con ese nivel de ingreso, la pobreza alimentaria (del orden de $20 \%$ de la población en la actualidad) habría probablemente desaparecido. Los altos niveles de informalidad en el mercado de trabajo, con todo lo que implican en términos de inseguridad e inestabilidad en el ingreso y falta de protección social, serían mucho menores: el tamaño de la economía sería tres veces el actual y al contarse con un acervo de capital mucho mayor para emplear a la fuerza de trabajo en ocupaciones de alta productividad, la informalidad estaría en realidad en vías de desaparición. Ese nivel de ingreso proveería de recursos varias veces superiores a los actuales para invertir en educación mientras que los menores niveles de pobreza contribuirían también a un menor rezago educativo. Lo mismo se aplica a la salud de la población y a la provisión de los servicios en esa área. El problema de la falta de financiamiento para las pensiones estaría resuelto en gran medida, con lo cual estaríamos en condiciones mucho mejores para enfrentar el envejecimiento de la población, cuya tasa de dependencia se elevará a partir de 2017. La violencia asociada al narcotráfico sería con seguridad mucho menor en la medida en que el crecimiento rápido, al proveer de amplias oportunidades de empleo e ingresos crecientes a los jóvenes, habría detenido y revertido el aumento del "ejército delincuencial de reserva”, para usar la expresión de Ciro Murayama, profesor de nuestra Facultad. Anteayer en la noche estaba viendo un programa en el canal once en el que Mario Luis Fuentes entrevistó a José Woldenberg, ambos miembros de nuestra comunidad universitaria, sobre el bajo grado de satisfacción de los mexicanos con su democracia (solo $40 \%$ de los mexicanos prefiere claramente un régimen democrático a uno autoritario; al resto le da igual o prefiere un régimen autoritario). Estoy convencido que ese grado de satisfacción, y el funcionamiento mismo de nuestra democracia, sería mayor si el desempeño de la economía mexicana no hubiera sido tan pobre durante la transición de las últimas décadas a la democracia.

¿Por qué dejó de crecer la economía mexicana? ¿Cómo puede México salir del estancamiento económico en que ha estado sumido en las últimas tres décadas? Por lo dicho anteriormente, pocas preguntas tienen tanta relevancia para el futuro de la sociedad mexicana. Y al mismo tiempo son preguntas en torno a las cuales no hay consenso en las respuestas que dan los economistas. En un libro de próxima publicación pretendo contribuir a su respuesta analizando 
Economía Informa núm. 383 noviembre - diciembre • 2013 - " " "

los fundamentos analíticos y empíricos de varias de las reformas económicas y sociales que el nuevo gobierno del presidente Peña Nieto ha emprendido con el fin de sacar a la economía mexicana de su trayectoria de lento crecimiento. Estas reformas han estado en el centro de la agenda para retomar un crecimiento económico más dinámico desde hace ya varios sexenios.

No tengo el tiempo necesario para reseñar las tesis de este libro. Si toman mis cursos de Economía Mexicana tendremos tiempo de sobra para hacerlo. Me limito a mencionar que la contribución del libro es en el terreno de las ideas. Con ello quiero decir que más que ofrecer una agenda alternativa de política económica, el trabajo se limita a analizar críticamente las bases analíticas y empíricas de varias de las tesis que inspiran la actual agenda para el crecimiento. El argumento central que expongo es que gran parte de la actual agenda de reformas no va a servir de mucho para salir del estancamiento y que hacerlo demanda cambiar de agenda. Lo que se opone a este cambio no son tanto los intereses creados sino las ideas que inspiran un diagnóstico equivocado de la realidad presente. Las ideas influyen de manera decisiva en la formulación de políticas económicas y con ello en el desempeño de las economías. Los políticos, decía Keynes, son con frecuencia y sin saberlo esclavos de las ideas de algún economista difunto. Además, la percepción que tienen de sus propios intereses los agentes económicos, y en particular las élites, se ve afectada por su visión de la economía y de los efectos de la política económica. En efecto, las ideas condicionan la autopercepción de las élites: como lo menciona Rodrik (2013), la reacción de los grupos de poder empresarial ante, por ejemplo, una expansión fiscal depende de si la perciben como un factor que va a impulsar la actividad económica o traducirse en mayor inflación. El primer paso para cambiar la agenda consiste entonces en reconocer que el diagnóstico actual está equivocado.

\section{Conclusión}

Volvamos a la pregunta inicial ¿Se han embarcado entonces en un bosque pantanoso repleto de arenas movedizas? Sí, y esto tiene varias implicaciones.

\footnotetext{
1) El progreso científico en el campo no es lineal. No hay que descartar viejas teorías por el simple hecho de que son viejas. Lo más nuevo y reciente no es necesariamente mejor que lo antiguo, puede incluso significar una regresión.

2) No hay una correspondencia estricta entre teoría e ideología. Dani Rodrik, uno de los economistas más rebeldes y heterodoxos en la academia norteamericana, tiene algo de razón cuando afirma
} 
que para ser progresista, nada mejor que ser neoclásico (es decir, dominar la teoría dominante en el campo).

3) Ni siquiera la investigación empírica y la economía aplicada nos pueden dar respuestas definitivas, dadas las dificultades de realizar experimentos controlados como aquellos a los que recurren las ciencias naturales.

4) Todo esto significa que hay que aprender mucho y de muchos sin descartar a la ligera distintos puntos de vista. Hay incluso que filosofar de vez en cuando.

Esto me lleva a una reflexión final. En el Economic Journal (septiembre de 1924, pp. 173-174), Keynes publicó un artículo obituario en ocasión de la muerte de su maestro Alfred Marshall; ahí Keynes ofreció una síntesis de la obra de Marshall y de las cualidades de un genuino economista:

El estudio de la economía no parece requerir ninguna virtud especializada, de una naturaleza inusualmente elevada. ¿No es, considerada intelectualmente, una ciencia muy fácil comparada con las ramas más altas de la filosofia o de las ciencias puras? Sin embargo, buenos economistas, o incluso competentes, son las aves más raras. ¡Una ciencia fácil en la cual muy pocos alcanzan la excelencia! La paradoja encuentra su explicación, quizás en que el economista Maestro debe poseer una rara combinación de virtudes. El economista debe alcanzar un estándar elevado en diferentes direcciones y debe combinar talentos que con frecuencia no se encuentran reunidos en la misma persona. Debe ser matemático, historiador, estadista, filósofo -en algún grado. Él tiene que entender símbolos y hablar con palabras. Debe contemplar lo particular en términos de lo general y tocar lo abstracto y lo concreto en el mismo vuelo de pensamiento. Debe estudiar el presente a la luz del pasado para los propósitos del futuro. Ningún aspecto de la naturaleza humana o de sus instituciones debe quedar enteramente al margen de su interés. Debe ser persistente y desinteresado de manera simultánea; soñador e incorruptible como un artista, y sin embargo a veces tan terrenal como un político.

Para bien o para mal, la economía tiene una gran influencia en el quehacer de los gobiernos, partidos políticos, y organizaciones no gubernamentales y, por esa vía, un enorme impacto en el bienestar de la sociedad. Hagamos lo mejor posible para que ese potencial de nuestra disciplina sea para bien. Para ello necesitamos rigor, de ahí la referencia a las matemáticas en la reflexión de Keynes, conocimiento empírico de la materia, de ahí la referencia a la historia, misión social y de servicio público, de ahí la referencia al estadista, y la pasión del soñador terrenal que es una manera particular de ser filósofo, un filósofo, como se nos ha definido por un gran historiador del pensamiento económico, Robert Heilbroner, un filósofo de la vida material. 